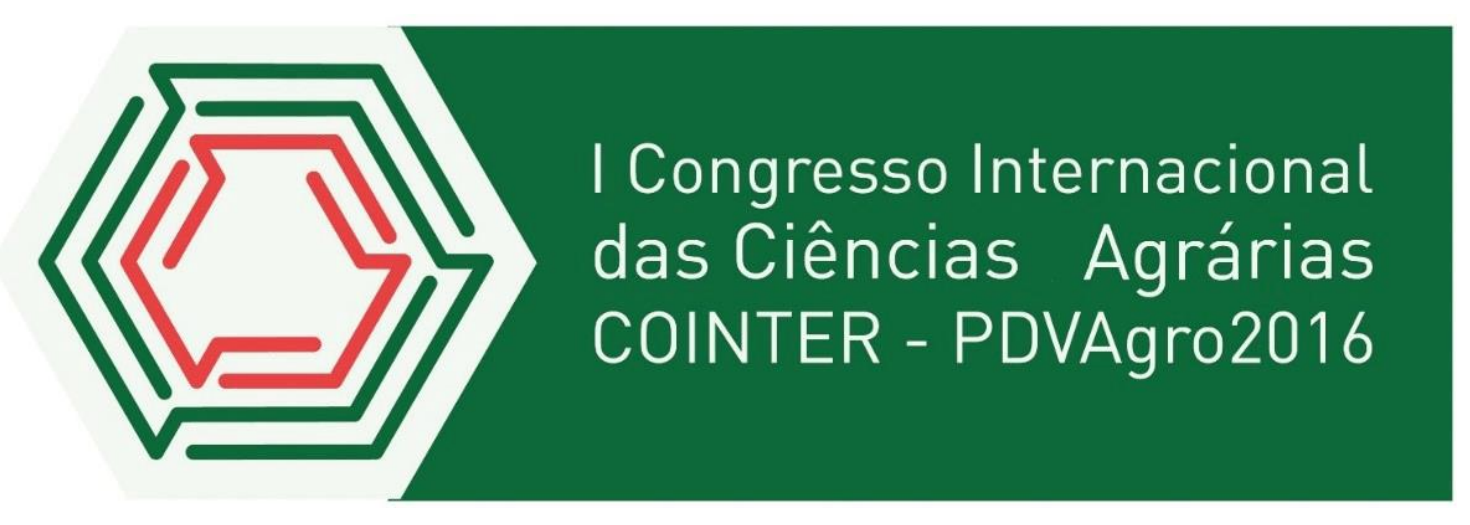

\title{
CIÊNCIA E TECNOLOGIA DE ALIMENTOS: UMA VIVÊNCIA DE TRÊS ESTUDANTES DE ESCOLAS PÚBLICAS NO CURSO DE AGROINDUSTRIA DO IFPE E NO PDVAGRO
}

\author{
Apresentação: Relato de Experiência
}

Tiago Edvaldo Santos Silva ${ }^{1}$; Maria Beatriz de Oliveira²; Ana Cláudia de Lima Medeiros $^{3}$; Daiane Firmino das Neves ${ }^{4}$; Erick Viana da Silva ${ }^{5}$

\section{Introdução}

A ciência e Tecnologia na área de alimentos é uma ciência de essencial importância à produção agrícola, pois trata-se de um ramo que busca alternativas em técnicas de produção que possam aumentar a qualidade da matéria prima que se beneficia e/ou processa, e, dessa forma, agregar valor ao produto final. E, por isso, o programa Despertando Vocações para Ciências Agrárias - PDVAgro, do IFPE, criou um grupo de trabalho de Ciência e Tecnologia do Alimento - GT:CTA. Diante disso, esse trabalho tem a finalidade de relatar a experiência de três estudantes que oriundas de escolas públicas, que conheceram o IFPE por meio do PDVAgro, e hoje, fazendo curso de Agroindústria, são integrantes do GT: CTA .

\section{Relato de Experiência}

As três estudantes envolvidas nessa experiência são frutos das ações do PDVAgro, que em 2015 aproximou diversas instituições públicas municipais e estaduais, do campo e da cidade, ao campus Vitória do IFPE. E hoje, por meio das políticas de acesso as Instituições Federais, ao buscarem sua formação profissional em outra cidade, contrariam os antigos índices de jovens filhos de trabalhadores/as que se profissionalizam, e o machismo que limita a mulher a estudar o mais perto possível de casa, onde esteja sob o campo de visão da família.

\footnotetext{
1. Estudante do Instituto Federal de Educação, Ciência e Tecnologia - tiagoedvaldo@hotmail.com;

${ }^{2}$ Estudante do Instituto Federal de Educação, Ciência e Tecnologia - maria00beatriz@gmail.com;

${ }^{3}$. Estudante do Instituto Federal de Educação, Ciência e Tecnologia - annacllaudia14@gmail.com;

4. Estudante do Instituto Federal de Educação, Ciência e Tecnologia - dayanne16neves@gmail.com;

5. Professor do Instituto Federal de Educação, Ciência e Tecnologia -erick.viana@vitoria.ifpe.edu.br.
} 
No IFPE-Vitória, durante o primeiro semestre do curso já estavam engajadas em atividades de pesquisa e extensão. Isso possibilitou participação delas em eventos regionais com apresentação exitosa de trabalhos (Imagem 2). Participaram também, de minicursos de boas práticas de fabricação e análise sensorial (imagem 1), por meio dos quais as estudantes puderam refletir sobre as técnicas de avaliação de um produto por meio da análise sensorial, uma técnica que se submete o produto aos sentidos humanos (visão, olfato e paladar). A avaliação é registrada por meio de fichas, que após serem sistematizados com base nas preferências, podem fazer chegar à agroindústria informações muito úteis, como a quantidade ideal a ser utilizada de água, sal ou açúcar, em determinada receita (ORMENESE et al., 2001).
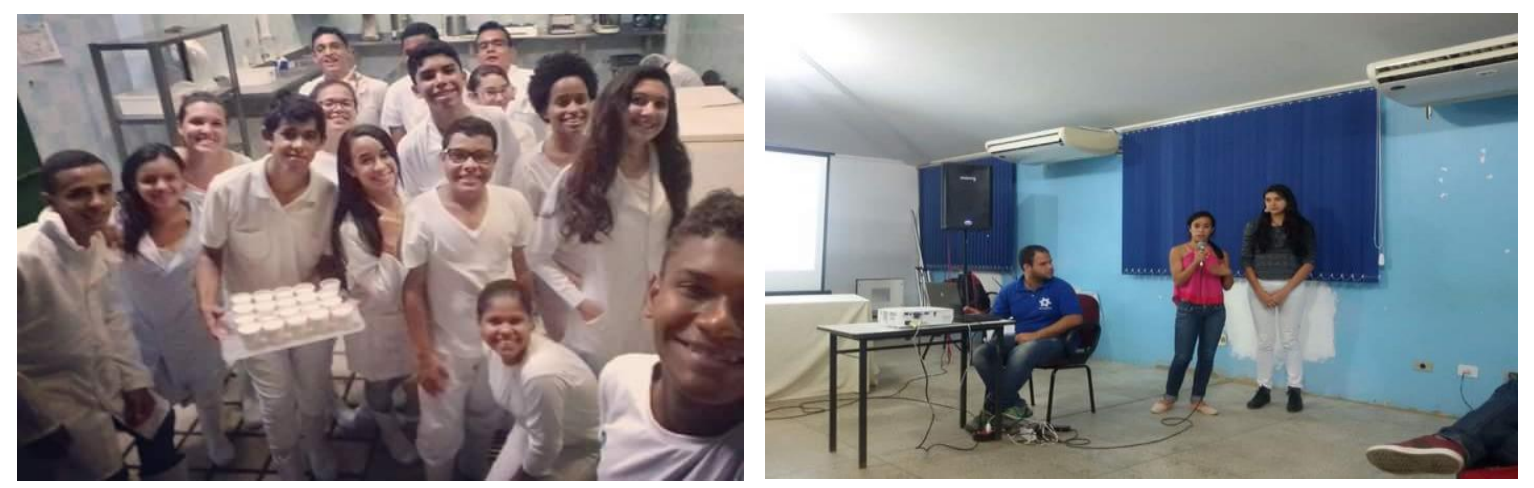

Imagem 1: Atividade Experimental. Fonte: Própria Imagem 2: Apresentação de trabalho em evento.

Não obstante a isso, refletiram também sobre os hábitos alimentares do brasileiro da atualidade, bem como buscar formas de atrelar qualidade nutricional ao alimentos que muitas vezes são produzidos tendo como prioridade a praticidade e o sabor (GALLAGHER et al., 2003).

\section{Considerações}

A atuação das estudantes em eventos extra curriculares na área de alimentos, tem contribuído para o desenvolvimento de uma formação mais fiel ás demandas do mundo produtivo. E indo além dos ganhos individuais, tais estudantes ao quebrarem as barreiras sociais, econômicas e de gênero, e ocuparem esses espaços na sociedade, contribuem para clarear os caminhos de possibilidades para as que hão de vir.

\section{Referências}

GALLAGHER, E. et al. Uso da metodologia de superfície de resposta para a produção de biscoitos de massa funcionais. Journal of Food Engineering. v.56, n.2-3, p.269$271,2003$.

ORMENESE, R.de C.S.C. et al.. Boletim Centro de Pesquisa de Processamento de Alimentos, v.19, n.2, p.277-300, 2001. Disponível em: <http://ojs.c3sl.ufpr.br/ 